\title{
A Proposition For Effective Integration Of Ethics Across The Business Curriculum
}

Mary Ann Boose, (E-mail: isboose@befac.indstate.edu), Indiana State University F. Peter Dean, (E-mail: fpd@joink.com), Indiana State University

\begin{abstract}
This paper proposes a model for providing business students with a rigorous, well-integrated, complete, and systematic approach to ethics that is grounded in critical thinking and presented in a progressive series of modules that are related to each other and to the specific business discipline of each business core course. Using this model, colleges and schools of business can take positive, cutting-edge steps toward developing a high quality, meaningful business ethics program. Companion studies examine two pilot initiatives. The first is an application of this model in core business classes and the second is an application in an upper level course that is an elective in a business major.
\end{abstract}

\section{Background: Three Models}

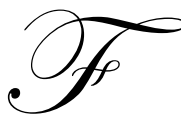

or over a dozen years, colleges and schools of business have wrestled with the question of how to better address the AACSB requirement of inclusion of ethics into their curricula. Three basic approaches have resulted: specific ethics courses; a distributed "ethics across the business curriculum" model; and an exclusive case study approach that eschews presentation of formal ethics in favor of case analysis. Each of these approaches has distinct advantages, and each has proven to suffer from distinct shortcomings. Although it is simplification of what is actually practiced in schools of business, it is useful to examine each of these approaches separately.

\section{The Specific Ethics Course Approach}

In order to address students' needs and AACSB requirements, some colleges and schools of business include specific ethics courses in their core requirements. These courses may be taught in business or in liberal arts (usually philosophy). They can present an excellent theoretical background for students which helps students to understand the variety of approaches that may be taken in addressing ethical issues.

There are three distinct advantages to this approach. First is ease of administration. Once a course is included in the curriculum, each student is required to successfully complete the course as part of any business major, thus assuring that each business student has had the opportunity to learn ethical principles and applications. Appropriate faculty are identified for the course, and administrative needs are minimal. This leads to the second advantage: competent authorities teach the course. Whereas most business faculty have little, if any, preparation in the principles or application of ethics, a specific course can be taught by individuals with expertise in the area. Finally, the ethics course will use ethics texts that cover the material in a rigorous, systematic manner. Clearly, this involves presentation of ethical theory; introduction to terminology; and application of ethical theory in a business context.

Unfortunately, isolating ethics in a separate course leads to an important, challenging consequence. There is a strong tendency of all involved, especially students, to view ethics as just one more course, unrelated to the rest of the coursework, and possibly not even of significance in the students' business careers unless they aspire to work

Readers with comments or questions are encouraged to contact the authors via e-mail. in the department of a corporate ethics officer. This consequence is seldom adequately addressed by business facul- 
ty since they, too, often view ethics as just one of the courses outside their own disciplines, and there is too little time to try to demonstrate how it should be integrated. Finally, when the course is taught outside the business area, most likely by philosophy professors, there is the possibility of disconnectedness similar to that experienced when statistics or business report writing is taught by non-business faculty. That is, few philosophy professors have enough business experience to convince students that the applications presented are realistic. The obverse situation may occur when business professors teach business ethics. They present convincing business cases but are sometimes weak on ethical theory. Students are disserved in both situations.

\section{The Distributed "Ethics Across the Business Curriculum" Approach}

The ethics initiatives at many AACSB-accredited colleges and schools of business eschew the establishment of a course devoted to business ethics in favor of a distributed "ethics across the business curriculum" approach. In this approach, all faculty are encouraged to incorporate ethics into each of their classes. Reports are created for accreditation purposes demonstrating the extent to which this integration is accomplished, and how it is addressed in each course. This approach has the important potential benefit of connecting ethics to its application in individual business disciplines. Integration into all, or most, business courses demonstrates the relevance of ethical theory and practice to business professionals and makes its importance immediately apparent. An additional advantage of this model is that it does not require dedication of scarce credit hours from a student's degree requirements. Nor does this approach require additional textbooks, as an increasing number of business texts include some consideration of ethics.

The laudable purpose of connecting ethics to business education and practice is, regrettably, thwarted by the many structural problems in the implementation of the distributed approach. The structural problems manifest themselves in issues of faculty, texts, time and energy constraints, administration/coordination, and pedagogical considerations. First, in the distributed approach the material is presented by individuals for whom ethics is outside their field of expertise. Without adequate preparation, the business professor is seldom much more knowledgeable than his or her students in the subject matter of ethics theory or implementation. This can lead, in the worst cases, to trivialization or simply to mistaken presentation of ethical concepts.

Second, business texts in most disciplines tend to cover ethics issues superficially, if at all. Often the material is relegated to sidebars, boxes, and end-of-chapter discussion questions. Although ethics is included in the text, the presentation sends the message to students and faculty alike that the material can easily be skipped without serious negative consequences.

This leads to the third disadvantage of the distributed approach that is the inclination of faculty and students alike, given the significant constraints of time and energy, to overlook the ethics material in favor of study of the course's technical material. Fourth, efforts by the faculty in any college or school of business are seldom coordinated in regard to teaching ethics, and the textbooks cannot coordinate ethics material across texts in a given discipline, let alone across business disciplines. This leads to ethics instruction that is disjointed and repetitive of simple concepts. If it is not possible to presume knowledge of basic principles in ethical theory or practice, then it is impossible to present higher level issues, concepts, or applications. This problem of administration or coordination leads logically to the pedagogical consequence that the ethics instruction presented serves students poorly because it does not cover the subject matter of ethics either broadly or deeply. Hence, faculty cover the material rapidly, possibly even trivializing ethics as an intellectual discipline; or they expound on the material, often relying on their own intuitive grasp of ethics (or that of their students) rather than presenting the work of the best thinkers in ethics.

Because the distributed approach is so common, many business textbook authors have begun to include coverage of ethics in their texts. In order to ascertain the extent of ethics theory and application in those texts, two studies have been completed in 1996 and 2000 (Dean). The study included all textbooks used in all classes in one school of business during the academic year. The first study's findings were not encouraging. The Business and Society text covered ethics well, but that is not a required course. None of the other texts were even adequate. The ethics presented in all other business textbooks was, at best, elementary. Most frequently, ethics was notable by its complete absence. Finally, in the worst cases, ethical theory was inaccurately described and applied in the business 
texts. Notably, the second survey, despite the interval of four years, failed to find any improvement. These findings reaffirm the shortcomings of depending upon the text material in the ethics across the curriculum approach.

\section{The Case Method Approach}

The final approach to ethics instruction in colleges and schools of business is the case method approach. In this approach cases involving ethical issues are presented to students. The students are expected to analyze the cases and then discuss them in class. The case method approach shares many of the strengths of the distributed approach. Cases are directly related to each business discipline, ethics cases are presented throughout the students' business curriculum, and the approach does not require the allocation of scarce credit hours to a separate business ethics course.

The disadvantages of the case method approach are also similar to the distributed approach. There is, however, an additional difficulty. The students are often required to apply ethics in their case analysis without benefit of exposure to formal ethical thought. This pedagogy would be strongly challenged in any business discipline. The importance of rigor would be emphasized, and the absence of underlying concepts and theory would be roundly criticized. In ethics, though, there appears to be a belief that there is an inherent moral sense that, with thought and discussion, will lead to acceptable ethical judgments. Unfortunately, such a common moral sense is not in evidence.

Finally, as with the distributed approach, in the case method approach the cases studied in various disciplines have no relation to each other, thereby again relegating the covered material to the most basic examples, and again (as with sidebars and boxes in the business texts) isolating ethics generally from the business disciplines. Again, given constraints of time and energy, it is reasonable to expect that the ethics cases may be the first items to be sacrificed when these constraints become binding. None of this is meant to suggest that cases have no place in teaching business ethics. But, cases alone are simply not adequate.

\section{The Challenge}

None of the widely employed approaches to the inclusion of ethics in the business curriculum described above meet the needs of the student because none succeeds in the two basic measures of effectiveness: adequate presentation of the subject matter of ethics, and; connectivity of that subject matter to business disciplines and practice. Faculty and administration who are concerned about these issues are seeking an alternative that meets both measures.

\section{Meeting the Challenge: A New Approach}

Given the potential advantages of each of the three approaches detailed above, and acknowledging the shortcomings and challenges associated with each, a new approach is necessary to better meet the needs of business students for a solid foundation of ethics theory and practice. Interestingly, among the approaches above, there are no conflicts among the advantages. That is, there are no two advantages that are mutually exclusive. Further, it should be noted that often the advantage of one approach is that it overcomes a disadvantage of one of the alternative approaches. Therefore, there should be no impediment to the creation of one approach that incorporates all the advantages, and if this is accomplished, the disadvantages as discussed above will be eliminated. Clearly, if this new approach can be accomplished, it would be expected to enhance students' understanding of ethics and the application to their professional lives. This will further result in improvement in this performance measure by the AACSB.

The balance of this paper details a proposed approach that capitalizes upon the best attributes of each of the current approaches. Since the advantages of each approach offset disadvantages of alternative approaches, any proposal that incorporates advantages of the specific course, distributed, and case approaches is expected to result in overcoming the disadvantages of all. The result is a proposal to implement across the curriculum a novel series of connected ethics presentations and cases that progresses through ethics theory in a logical, sequenced, progressive manner. Each module is presented by a team of instructors; one with expertise in ethics and one with expertise in a 
specific business discipline. They are coordinated across the business curriculum, and are tied to the students' normal progression through business courses from core to capstone classes. Ethics instruction is directly applied to the business coursework.

\section{Overview}

One faculty member, whose expertise is in the field of ethics, coordinates and presents the theory and applied material in ethics. He or she does this within the core courses in the business curriculum, and may extend the work to the basic, intermediate, and capstone courses in each of the curricula of the various business majors. This ethics professor works closely with other business faculty to integrate business course material into the ethics cases presented, and to time the presentations to meet the needs of the business course faculty and students. Throughout this process, the business faculty are encouraged to identify ethical issues and dilemmas specific to their discipline that would make the most interesting and relevant addition to their students' learning.

The proposed program appoints one or more faculty member(s) full- or part-time depending on the size of the college or school of business and upon the extent of the ethics program to be created. This ethics professor is responsible for creating the plan that will provide ethics theory and application throughout the students' progression through their business coursework. He or she then presents a set of theory modules, including cases, to all core business classes. The module set is the key to the progression of ethics theory from the simple to more complex. It is also the method of tying the ethics theory to business applications, and, more specifically, to applications relevant to the business course hosting the presentation of each module.

The module set starts with basic ethics concepts needed for all later work, and introduces the mythical company that will provide the site of a continuing series of cases throughout the set of modules. By thoroughly introducing the ethics foundational concepts and terms in early business courses, often the two-course sequence in accounting, it can be expected that all students will acquire a rigorous, thorough understanding upon which they can build during their remaining four or five semesters of business coursework. This avoids the duplications and gaps that exist in the distributed and cases approaches. Further, it allows progressive work including upper level concepts and applications that are not currently found in the programs that use these approaches. By introducing one hypothetical company for use throughout the modules, efficient use is made of class time throughout the students' semesters on campus. One set of institutional information can be used as background for finance, accounting, marketing, management, MIS, economics, insurance, real estate, and other ethics applications. Indeed, no discipline need be overlooked with this approach.

The intermediate level modules introduce various ethics theories and applications into the principles courses such as marketing, finance, and management. The capstone ethics work is finished in the capstone business strategy course. Given this basic plan, it is possible to create more discipline-specific modules for any business disciplines that might elect additional work in ethics theory and application. For example, to meet accounting requirements, an additional, coordinated set of modules might be included in the audit and tax courses that are required of accounting majors.

\section{Key Features of a Proposed Program}

The program uses a single mythical company for all cases. This ties the modules together with the same cast of characters, mission, organizational structure, products, market, etc. The company's organization, departments, and divisions can be tied explicitly to the disciplines required at the school of business. This, in turn, may lead to related, discipline-specific exercises within the core coursework, e.g., analyzing the marketing plan for the company, its international business relationships, or its financial statements. Familiarity with the mythical company reduces study time and presentation time necessary because there is no need for students to learn, or assume, new case backgrounds for each ethics case. This will also reduce the propensity of faculty and students alike to be distracted into discussions of background and setting rather than of the ethical issues being presented. It allows a richer set of material to be used, while simultaneously minimizing the time required for faculty and students to prepare, present, and evaluate case analyses. 
In this new approach, ethics theory progresses both in topics covered and in the level of sophistication throughout students' academic work. All school of business majors will have common basic ethics modules in their core courses, with more advanced ethics modules presented in the capstone strategy course. If the approach is expanded into particular majors, then the students can be exposed to additional intermediate modules that build within the particular discipline, culminating in that discipline's capstone experience course. This enhances the students' understanding of the relevance of ethics to their studies and to their careers. Ethics is interlaced with every core business discipline, overcoming the disconnectedness experienced in each of the current approaches. Because of the close relationship between the cases and the coursework, the ethics cases reinforce the principles of the host business class, negating the tendency to minimize work on ethics in favor of work on the business discipline.

In the new approach, cases are appropriately related to the disciplines in which they are presented, and to an increasing level of ethical sophistication. For example: the ethics modules presented in the core course in finance would incorporate financial concepts and the case would involve ethical decisions made by professionals in the company's finance department. The level of ethical sophistication in this module would be higher than that of the module presented in the prerequisite accounting courses. Except for the dedicated courses approach, no current approach offers this advantage. In the interest of breadth of coverage each module can also include, possibly by reference, published "real world" cases in the host discipline.

The new approach can include a web site that students can use as a resource throughout their college work. This site can include reference material such as an ethics glossary; an outline of the program and its modules as they relate to the business curriculum; and background data on the mythical company including its history, financial data, personal sketches of managers, organizational structure, and plant and office descriptions.

\section{Implementation: Program Development}

A series of joint ventures between the business ethics professor and interested faculty from the each of the business disciplines is necessary to define and develop aspects of the program on any campus. This work of the implementation team will enhance interdisciplinary cooperation within the college or school of business as it prepares the underlying structure and course material and protocols. Depending on the size of the college or school, a series of implementation steps can be identified to allow partial implementation, modification and enhancements based on the particular environment, and then full implementation building on and capitalizing on the uniqueness of the specific university and campus location.

At a minimum, a program of ethics integration as proposed above would require that the implementation team, or sub-groups from the team and other interested parties, complete the following steps.

1) Define the ethical concepts to be included in the program. (Ethicist leads.)

2) Define the core courses to be included in the program. (Discipline faculty lead.)

3) Determine the courses in which each concept should be covered. (Cooperative.)

4) Develop appropriate cases. (Discipline faculty lead.)

5) Choose appropriate readings. (Ethicist leads, discipline faculty contribute from their literature.)

6) Develop appropriate student materials. (Ethicist leads, discipline faculty review for discipline-specific content and details.)

7) Develop appropriate instructor materials (Ethicist leads, discipline faculty communicate with peers in their disciplines.)

8) Use these materials in class and report on results. (Cooperative, report to dean or other constituents.)

9) Write a joint paper describing "The Integration of Ethics Across the Business Curriculum ... in each discipline" (Cooperative. Discipline faculty lead on their conferences and publications.)

10) Join in writing a master document that describes the whole program, its development, and its practical implementation in each discipline. (Dean or administrative oversight.)

\section{Implementation: Faculty Team Coordination}


One of the anticipated benefits of the proposed program is a greatly enhanced interdisciplinary faculty cooperation. Although the ethics faculty member serves as the ethics resource person for the entire program, he or she will develop each case with cooperation and input from faculty who teach each of the host courses. Participation in the development of the material to be presented in each course will lead to familiarization with the company on which cases are based and with the ethics issues to be presented in the course. The process of this preparation provides more ethics theory and application to the faculty members than they would otherwise obtain in preparation of the cases in their discipline's texts, thus leading to a better understanding of at least that subset of ethical theory.

In addition to background preparation of the ethics material, and to the coordination of the entire set of modules, the ethics faculty member is also expected to lead class discussions of the ethics material. Clearly, the course instructor would shoulder responsibility for introduction of the discipline-specific aspects of the module and the application to the discipline. Students could be expected to write reviews of the required readings, videos, or other information. Further, students could be expected to create case analyses, which may be group exercises, and to discuss their work in class.

The ethics faculty member could provide as much additional ethical background as each course faculty member may choose to request. Further, explanation of connections to other modules with which the students have become familiar can be provided in documentation or in briefings. Comments on cases may be provided to assist the course faculty as they grade the assignments, or assistance in grading may be offered. Comments on the required readings may be provided as wished by course faculty. A separate, password protected, section of the ethics web site can provide substantial support for course faculty.

\section{Anticipated Benefits}

For students, this program provides a competent, thorough, and deep education in ethics theory and application that is integrated into the business curriculum. This approach is expected to enable students to see the importance of the subject matter to the disciplines they are studying and to their lives and careers. This prepares them for lifelong learning and application of ethics theory to their work. The material presented progresses from basics to advanced topics with minimal repetition or gaps in coverage. It uses the breadth of the business curriculum to explore a broad set of ethics theories and case studies, consistently demonstrating the relevance and importance of ethical issues.

For faculty, there is relief from the necessity of preparing and presenting material that is outside their expertise. The program allows them, in conjunction with the ethics professor, to teach business ethics systematically, in a manner that is well integrated into their courses, and is thoroughly supported. For those who are interested in broadening their own understanding of and expertise regarding the ethics material, there is a resource colleague who is motivated to provide relevant material and guidance. For those who are interested in interdisciplinary research, there is the opportunity to apply ethics to their own discipline, or to conduct empirical research concerning ethical attitudes and practices in their discipline.

For the college or school of business, the program provides many benefits. The program provides an innovative, integrated, discipline-related, systematic, sequenced program for teaching ethics across the business curriculum that exceeds the expectations of students, their parents, employers, and accreditation authorities. Interdisciplinary cooperation in teaching and research among faculty members is an additional benefit.

\section{Opportunities for Further Study}

Beyond the obvious matters of improvement of the proposed idea, approval by various authorities, and the undoubted complexities of implementation, there are some specific issues regarding the proposed program that should be addressed. For colleges and schools of business that allow non-business students to minor in business disciplines, there will be issues of sequencing, and thoroughness of the ethics material they receive. They may miss some of the basic ethics material and modules. They may also miss some of the intermediate and/or advanced material, leading to an incomplete background and knowledge, and thus possible misunderstanding that they now know 
business ethics. A similar set of issues will exist for students who transfer in with some business courses on their transcript. They will have missed the basic ethics material and modules, necessitating support systems to enable them to establish a foundation equal to that of their peers. A resource of documents, either on the web site, available on reserve at the university library, or available in the bookstore can help alleviate this lack of background information.

Despite its integration into and across the business curriculum, it is necessary to devise a system to evaluate the ethics program on its own merits. A system that parallels the one already in place at the particular institution should be created to measure the accomplishments and effectiveness of the ethics program. Likewise, if a baseline has been established for the assessment of the business curriculum as it currently exists, it would be interesting to learn what additional benefits accrue to that curriculum from the inclusion of this ethics program. For example, are the students able to better integrate their business thinking as a result of this integrated ethics program? Are the students better at case analysis because they have had so much more experience in it? Are the students better critical thinkers? Will they become more effective life-long learners?

Although this proposal is made for the undergraduate curriculum, there is an opportunity to develop a similar program for masters-level business programs. Likewise, certificate programs, high school honors seminars, and continuing education programs developed for industry might wish to incorporate ethics programs or modules.

Finally, this is a long-term project, with implementation likely starting in sophomore classes, and continuing to the final senior semester. It requires the involvement of a significant portion of the faculty of the college or school of business. If it is to be successful, the resources and support necessary for the program must be committed early for an extended period. Outcomes assessment should be measured as the implementation progresses, but final judgment cannot be accomplished until the full program is implemented and adjusted to fit the needs of the campus, faculty and students involved. This should allow the use of the initial measures on the initial, experimental class to improve the program itself. As with many collegiate outcomes assessment initiatives, a much longer time frame is required for any measurement of overall success.

\section{Bibliography}

1) Boose, Mary Ann and F. Peter Dean. Classroom Application of the Hunt - Vitell Model to Business Ethics. Proceedings of the International Applied Business Research Conference. March 2000.

2) _ . Demonstration of the Hunt - Vitell Model: Business Ethics Case Analysis. Proceedings of the International Applied Business Research Conference. March 2000.

3) Dean, F. Peter and Max Douglas. An Ideological Comparison of Deming's Management Philosophy and Virtue Ethics. Ethics and Critical Thinking Journal, December 15, 2000.

4) _. Should We Teach Business Students That Utilitarianism Is An Appropriate Basis For Ethical Decision Making? Presented at the International Association for Business and Society. March 2001. Sedona, AZ.

5) Dean, F. Peter. The Ethics of Teaching Ethics in Schools of Business. Proceedings of The International Applied Business Research Conference. March 2001.

6) Jennings, Marianne M. What's happening in business schools? The Public Interest, fall 1999.

7) Paul, Richard. 1995. Critical Thinking: How to Prepare Students for a Rapidly Changing World. Foundation for Critical Thinking. Santa Rosa, CA.

8) Rachels, James. 1993. The Elements of Moral Philosophy, 2nd ed. McGraw-Hill, Inc. New York.

\section{Appendix A}




\section{Typical Module Presentation To Students}

1) A 4-page handout with approximately the following format:

Page 1 - Review and Introduction;

Pages 1 \& 2 - New Ethical Theory;

Pages $3 \& 4$ - Application of ethics to the business discipline, written case;

Page 4 - Glossary of new ethics terms, annotated list of further readings.

2) Case and Leading Questions for discussion. It is anticipated that PowerPoint will be used for the case presentation in class to improve the student's sense of realism. It is also possible to send carefully planned and timed e-mail messages (from putative company managers or other interested parties) to students to increase this effect. Cases will focus on discipline related projects or decisions with ethical implications natural to those projects. Some cases may, of course, take the form of the traditional ethics case, i.e., what to do about an ethically poor or harmful act.

3) Required readings, films, or videos related to the issues presented in the sections on ethical theory and to its application to the discipline. (From the Annual Editions series, discipline related journals, etc.)

The ethics instructor is expected to lead class discussion of the theoretical ethics material and the course instructor will participate in discussion of its application to the discipline. Students are expected to write reviews of the required readings or videos, and a case analysis (these may be group exercises) and to discuss their work in class.

\section{Appendix B}

\section{Instructor Support}

1. Additional information on ethical theory. (Rachels,1993, is a primary source)

2. A complete reference set of ethics modules; both those designed for students and those for instructors.

3. Explicit explanation of connections to other modules.

4. Comments and leading questions on cases.

5. Comments and questions on required readings.

6. An annotated list of references

7. PowerPoint slides and other presentation materials. 